Louisiana State University

LSU Digital Commons

Faculty Publications

Department of Chemistry

$1-2-2010$

\title{
Bilitrienones from the chemical oxidation of dodecasubstituted porphyrins
}

Owendi Ongayi

Louisiana State University

M. Graça H. Vicente

Louisiana State University

Brahma Ghosh

Louisiana State University

Frank R. Fronczek

Louisiana State University

Kevin M. Smith

Louisiana State University

Follow this and additional works at: https://digitalcommons.Isu.edu/chemistry_pubs

\section{Recommended Citation}

Ongayi, O., Vicente, M., Ghosh, B., Fronczek, F., \& Smith, K. (2010). Bilitrienones from the chemical oxidation of dodecasubstituted porphyrins. Tetrahedron, 66 (1), 63-67. https://doi.org/10.1016/ j.tet.2009.10.098

This Article is brought to you for free and open access by the Department of Chemistry at LSU Digital Commons. It has been accepted for inclusion in Faculty Publications by an authorized administrator of LSU Digital Commons.

For more information, please contact ir@lsu.edu. 
Louisiana State University

LSU Digital Commons

Faculty Publications

Department of Chemistry

$1-2-2010$

\section{Bilitrienones from the chemical oxidation of dodecasubstituted porphyrins}

Owendi Ongayi

Louisiana State University

M. Graça H. Vicente

Louisiana State University

Brahma Ghosh

Louisiana State University

Frank R. Fronczek

Louisiana State University

Kevin M. Smith

Louisiana State University

Follow this and additional works at: https://digitalcommons.Isu.edu/chemistry_pubs

\section{Recommended Citation}

Ongayi, O., Vicente, M., Ghosh, B., Fronczek, F., \& Smith, K. (2010). Bilitrienones from the chemical oxidation of dodecasubstituted porphyrins. Tetrahedron, 66 (1), 63-67. https://doi.org/10.1016/ j.tet.2009.10.098

This Article is brought to you for free and open access by the Department of Chemistry at LSU Digital Commons. It has been accepted for inclusion in Faculty Publications by an authorized administrator of LSU Digital Commons.

For more information, please contact ir@lsu.edu. 


\title{
Bilitrienones from the chemical oxidation of dodecasubstituted porphyrins
}

\author{
Owendi Ongayi, M. Graça H. Vicente, Brahma Ghosh, Frank R. Fronczek, and Kevin M. \\ Smith \\ Department of Chemistry, Louisiana State University, Baton Rouge, LA 70803, USA.
}

\begin{abstract}
The structure of the ring-opened product from direct oxidation of meso-tetraarylporphyrins has been controversial for three decades. Herein we show that bilitrienones $\mathbf{2}$ are obtained from oxidation of metal-free dodecasubstituted porphyrins 1 in the presence of sodium nitrite, trifluoroacetic acid and air oxygen. The presence of the para-nonyl groups in $\mathbf{1 b}$ stabilized the corresponding bilitrienone $\mathbf{2} \mathbf{b}$, which was characterized by X-ray crystallography. In the absence of the para-nonyl groups bilitrienone 2a undergoes a rapid hydration reaction, giving biladienone $\mathbf{3 a}$ as the major isolated product. The molecular structures of $\mathbf{2} \mathbf{b}$ and $\mathbf{3 a}$, and. the photochemical isomerization of $\mathbf{3 a}$ are discussed.
\end{abstract}

\section{Introduction}

The meso-oxidation of metallo-porphyrins and -chlorins has been investigated for several decades in order to gather insight into the important biological processes of heme catabolism, ${ }^{1}$ chlorophyll degradation ${ }^{2}$ and formation of algal biliproteins. ${ }^{3}$ The open-chain oxygenated tetrapyrroles, often designated generically as bile pigments, perform important biological functions, for example as the chromophores in biliproteins, $4^{-} 6$ and have been proposed for various applications, including as antiviral and antioxidant agents. $7^{-9}$ In living organisms, bile pigments (e. g. biliverdins) are formed from the highly specific enzymatic oxidation of heme, catalyzed by heme oxygenase. ${ }^{10,} 11$ On the other hand, the chemical syntheses of bile pigments can be achieved from pyrromethenone $12^{-} 14$ or dipyrromethene synthons, ${ }^{15}$ or from chemical oxidation of porphyrins and metalloporphyrins using $\mathrm{O}_{2}$ in the presence of ascorbic acid or hydrazine (so-called coupled oxidation of iron porphyrins), 16, 17 thallium(III) or cerium(IV) trifluoroacetate salts, $18^{-} 20 \mathrm{~N}_{2} \mathrm{O}_{4} 21$ or sodium nitrate and trifluoroacetic acid,22 hydrogen peroxide ${ }^{23}$ or meta-chloroperoxybenzoic acid (mCPBA) in pyridine, 24 by reactions of metalloporphyrin $\pi$-cation radicals with nucleophiles, 25 or from photo-oxygenation. $26^{-} 28$ Whereas the structures of the oxidation products from boctasubstituted porphyrins (e.g. octaethylporphyrin and protoporphyrin-IX) are well documented and were shown to involve the formation of formyl-bilitrienones, those from the related meso-substituted porphyrins, such as meso-tetraphenylporphyrin (TPP), have been subject of controversy for over three decades. The first spectral evidence for the formation of a bilitrienone from TPP was reported in 1980 by one of us. ${ }^{26}$

(c) 2009 Elsevier Ltd. All rights reserved.

"Corresponding author. Tel.: +1-225-578-7442; fax: +1-225-578-3458; kmsmith@1su.edu.

Publisher's Disclaimer: This is a PDF file of an unedited manuscript that has been accepted for publication. As a service to our customers we are providing this early version of the manuscript. The manuscript will undergo copyediting, typesetting, and review of the resulting proof before it is published in its final citable form. Please note that during the production process errors may be discovered which could affect the content, and all legal disclaimers that apply to the journal pertain. 
This compound was presumably unstable and rapidly underwent reversible addition of water, methanol or ethanol at the a-methine carbon bridge, forming the corresponding biladienones. ${ }^{28}$ Indeed, the involvement of a bilitrienone intermediate was controversial, since no NMR data were available for this product or its metal complexes. More recently, during our investigation of the oxidative ring-opening reaction of dodeca-substituted porphyrin $\mathbf{1}$, we isolated and characterized the air- and solvent-stable $\mathrm{Ni}(\mathrm{II}), \mathrm{Zn}(\mathrm{II})$ and $\mathrm{Cu}(\mathrm{II})$ complexes of its corresponding bilitrienone. ${ }^{22,24}$

\section{Results and Discussion}

The chemical oxidation of dodecasubstituted porphyrin 1a using 6 equiv of $\mathrm{NaNO}_{2} / \mathrm{TFA}$ in the presence of air gave the corresponding benzoylbiliverdin $\mathbf{2 a}$, which was too unstable to isolate in pure form, due to its readily hydration to produce $3 \mathbf{a}^{22,23}$ Two distinct isomers of 3a, purple and pink in color, were isolated in about 3:1 ratio after work-up of the oxidation reaction and purification by column chromatography. Both isomers showed broad absorption bands in the UV-Vis, indicating significant conformational flexibility. Mizutani and coworkers have also isolated the purple and pink fractions upon chemical oxidation of iron TPP and reported that the pink benzoylbiliverdin could be photoisomerized to the purple benzoylbiliverdin, while the reverse isomerization did not proceed. ${ }^{25}$ Heating the mixture of isomers 3a in the presence of a metal salt results in dehydration and metalation with formation of the corresponding stable metal complexes of $\mathbf{2 a} .{ }^{23}$ Under the same conditions, porphyrin $\mathbf{1 b}$ was also oxidized, but in this case benzoylbiliverdin $\mathbf{2 b}$ was more resistant to spontaneous hydration than $\mathbf{2 a}$, and was therefore isolated successfully in $70 \%$ yield, along with $15 \%$ yield of the corresponding hydrated form $\mathbf{3 b}$. Separate studies by Smith, $17^{-} 19$ Fuhrhop, 20 and Cavaleiro ${ }^{16}$ have shown that 5,10,15,20-tetraphenylporphyrin (TPP) is oxidized to give the corresponding biliverdin which rapidly undergoes nucleophilic addition of water to produce the corresponding hydrated biliverdin.

The $300 \mathrm{MHz}{ }^{1} \mathrm{H}-\mathrm{NMR}$ spectra of benzoylbiliverdins $\mathbf{3} \mathbf{a}^{24}$ showed the asymmetry of both tetrapyrroles, i.e. three $\mathrm{N}-\mathrm{H}$ signals and one $\mathrm{O}-\mathrm{H}$ signal that appeared at 11.5, 11.2, 9.0 and $6.0 \mathrm{ppm}$, respectively; all of these ${ }^{1} \mathrm{H}-\mathrm{NMR}$ absorptions disappeared upon performing a deuterium oxide shake on the tetrapyrrole that was purple in color. The ${ }^{13} \mathrm{C}$ spectrum of $\mathbf{3 a}$ showed a benzoyl carbonyl peak at $187 \mathrm{ppm}$, the lactam carbonyl at $174 \mathrm{ppm}$ and a quaternary carbon peak at $75 \mathrm{ppm}$. The tetrapyrrole that was pink in color, on the other hand, gave a ${ }^{1} \mathrm{H}$ NMR spectrum with two $\mathrm{N}-\mathrm{H}$ peaks appearing at 12.5 and 9.46, two distinct singlets, one of them corresponding to the hydroxyl group, appeared at 4.1 and 3.7 $\mathrm{ppm}$. A deuterium oxide shake resulted to the disappearance of the two $\mathrm{N}-\mathrm{H}$ protons and one of the singlet peaks that had previously appeared at $4.1 \mathrm{ppm}$. The ${ }^{13} \mathrm{C}$ spectrum of the pink tetrapyrrole ${ }^{24}$ differed only slightly from that of the purple tetrapyrrole with very similar carbonyl frequencies appearing at 187 and $172.4 \mathrm{ppm}$, along with a quaternary carbon peak at $77.7 \mathrm{ppm}$. Characteristic benzoylbiliverdin fragments were obtained by high resolution EI-MS for both chromophores; these had M+Na ion peaks at $\mathrm{m} / z, 903.4249$ and 903.4224 for the pink and purple tetrapyrroles, respectively. Oxidations were also carried out using anhydrous methanol, ethanol, and methylamine to quench the reactions, and while methylamine gave no addition product at all, the methanol and ethanol adducts were formed in almost negligible amounts as inferred from the appearance of near-baseline $m / z 913$ and 927 peaks. Both steric and electronic (such as solvents being less nucleophilic than $\mathrm{H}_{2} \mathrm{O}$ ) effects may be invoked to account for the above observations. Unfortunately, the amounts of the above products obtained were too little for any further analyses to be performed. 


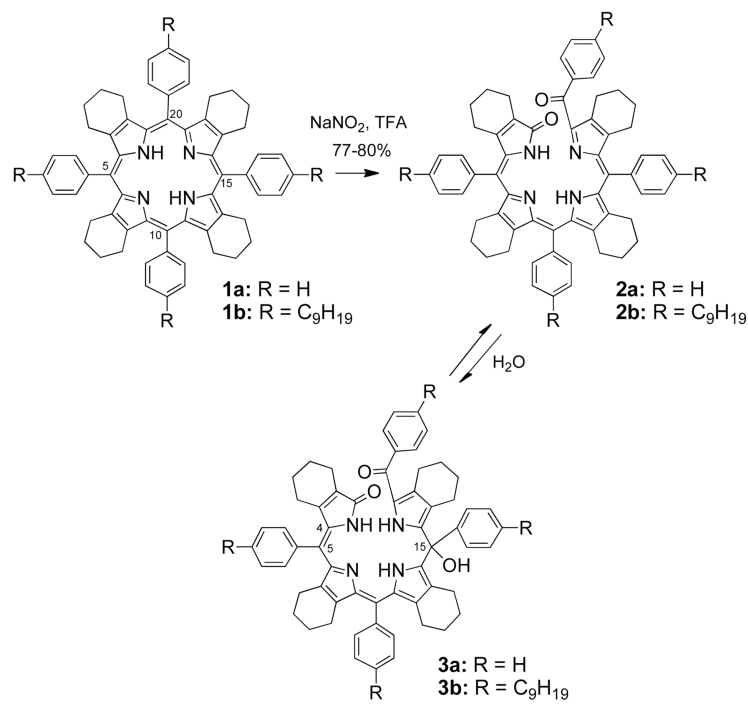

Biliverdins usually have the helical all-syn conformation due to an efficient intrachromophoric hydrogen bond system based on the N-H....N-H network. Studies carried out on biliverdin IX $\alpha$ esters have shown the $\varepsilon_{(\mathrm{vis})} / \varepsilon_{(\mathrm{UV})}$ ratio to be a function of the verdin molecular extension. An increase in ratio indicates a change in the porphyrin-like helically coiled form $(5 \mathrm{Z}, 10 \mathrm{Z}, 15 \mathrm{Z})$ to a more extended form, (e.g., 5Z, 10E, 15Z or 5E, 10Z, 15Z), where the ratio is similar to that of a polyene. ${ }^{26-} 28$ In our study, the $\varepsilon_{(\mathrm{vis})} / \varepsilon_{(\mathrm{UV})}$ of the purple and pink biliverdin conformers was 0.47 and 0.64 respectively indicating a more stretched conformation for the pink conformer than the purple one. All free biliverdins normally tend to adopt the ZZZ helicoidal conformation with an $\varepsilon_{(\mathrm{vis})} / \varepsilon_{(\mathrm{UV})}$ ratio of 0.25 in agreement with molecular orbital calculations.29-33 Helicoidal (ZZZ)-biliverdins could be photoisomerized to their extended EZZ or EZE conformers but the latter reconverted back to the helical forms. ${ }^{34}$ This explains the $\sim$ 3:1 isolation of the violet biliverdin 3a versus the much more polar pink conformer of $\mathbf{3 a}$.

When porphyrin $\mathbf{1 b}$ was oxidized under similar conditions to those for $\mathbf{1 a}$, only bilatrienone $\mathbf{2 b}$ and biladienone $\mathbf{3 b}$ were obtained, with no traces of the pink conformer of $\mathbf{3 b}$. This could be a result of the bulky alkyl substituent on the phenyl ring which do not favor the EZ isomerization of the $\mathrm{C} 4-\mathrm{C} 5$ bond; similar results were reported for etiobiliverdin by Mizutani and coworkers who reported that the energy difference between the ZZZ and EZZ isomer is ascribed to the steric repulsion between the $\beta$-alkyl groups and the pyrrole ring. ${ }^{25}$ We believe that the sole product of the chemical oxidation of porphyrin $\mathbf{1 b}$ is bilatrienone $\mathbf{2 b}$ along with some traces of starting material. However upon workup and chromatographic purification, biladienone $\mathbf{3 b}$ is isolated after addition of a water molecule across the methine carbon bridge. This could be further argued with the fact that upon subjecting $\mathbf{3 b}$ to higher temperatures e.g., $40^{\circ} \mathrm{C}$, compound $\mathbf{2} \mathbf{b}$ was isolated. This was confirmed by thin layer chromatography and UV-vis and ${ }^{1} \mathrm{H}$ NMR spectroscopy.

A final confirmation of the molecular structure of biliverdin $\mathbf{2 b}$ and the purple benzoylbiliverdin 3a was provided by X-ray crystallography. Figure 1 shows the X-ray structure of benzoylbiliverdin $\mathbf{2 b}$, with arbitrarily small $\mathrm{C}$ atoms for the n-nonyl groups. The central part of the molecule has a helical shape. Internal N-H...N hydrogen bonds allow each $\mathrm{C}(\text { pyrrole })^{2}$ group to be reasonably planar, with mean deviations of 0.06 and $0.11 \AA$ for these 11-atom fragments. However, these two planes form a dihedral angle of $29.3(2)^{\circ}$ due to the helical twist of the acyclic molecule, which also brings phenyl groups of $\left(\mathrm{C}_{9} \mathrm{H}_{19}\right) \mathrm{Ph}$ substituents at opposite ends of the molecule into edge-to-face contact. Parameters of this 
interaction are C...centroid distance $3.456 \AA$ and C-H...centroid angle $147^{\circ}$. Two of the nonyl groups are extended, while the other two are quite tortuous, as shown schematically in Fig. 1.

An examination of the X-ray structure of biliverdin 3a (obtained by slow diffusion of hexane into a solution of chloroform) shows the compound to be a biladienone, with the third meso-carbon (C15) a tetra-substituted one and bearing a hydroxyl group (see Figure 2). The existence of the $-\mathrm{OH}$ group is thus unequivocally established and corroborates the structural conclusions reached from ${ }^{13} \mathrm{C}-\mathrm{NMR}$ data, which showed the presence of a quaternary meso- carbon at $\delta 75 \mathrm{ppm}$. Within a single crystal, two molecules of the biliverdin associate with each other to form intermolecularly hydrogen-bonded pairs (Figure 3). Triads of hydrogen bonds exist about an inversion center, with the participating groups being the lactam unit on one molecule and the benzoyl carbonyl, the pyrrole $-\mathrm{NH}$, and most importantly, the meso-OH on the other. The meso-OH $\cdots O \mathrm{O}$ (1) bond, though slightly extended, lies at a nearly perfect hydrogen-bonding angle of $\sim 179$ thus allowing for moderately strong hydrogen bonds; the remaining hydrogen bonds lie within $20 \%$ of the optimum angle of $180^{\circ}$. Stabilization offered by the intermolecular association may be the raison d'etre for the hydroxyl group and may explain the readiness of the initially formed bilatrienone 2a to add a molecule of water across one of its double bonds to give the above biliverdin. The same, along with steric factors, may also explain why oxidations performed in methanol, ethanol, or methylamine media almost completely failed to give the corresponding addition products or gave so only in negligible quantities.

One consequence of the hydrogen bonding is that it predisposes the $\mathrm{C}(4)=\mathrm{C}(5)$ double bond into an $E$-configuration, making the (EZ)-biladienone arrangement the most stable one for this biliverdin. This, however, does not discount the possibility of various other arrangements that may arise out of bond-rotation about the above double bond. Our theoretical calculations (B3LYP/6-31G*) do in fact predict the existence of various stereoisomers of the title biliverdin, which differ in energies by $6-10 \mathrm{Kcal} / \mathrm{mol}$ at room temperature, and may explain why the novel verdin is obtained as two different colored forms - namely the violet and the pink. In fact, similar isomeric biladienones were obtained by Mizutani et al., although from a $\beta$-unsubstituted porphyrin (TPP), and under oxidation conditions different than those reported herein.

\section{Experimental}

Silica gel 60 (70-230 and 230-400 mesh, Merck) or neutral alumina (Merck; usually Brockmann Grade III) were used for column chromatography. Analytical thin layer chromatography (TLC) was performed using Merck 60 F254 silica gel (pre-coated sheets, $0.2 \mathrm{~mm}$ thick). Reactions were monitored by TLC and spectrophotometry. ${ }^{1} \mathrm{H}-\mathrm{NMR}$ spectra were obtained in deuterochloroform or acetone- $\mathrm{d}_{6}$ solution, using a Brucker 250 or 400 $\mathrm{MHz}$ spectrometer; chemical shifts are expressed in ppm relative to residual chloroform $(7.26 \mathrm{ppm})$ or internal TMS (0 ppm). Unless otherwise stated, electronic absorption spectra were measured in dichloromethane solution using a Hewlett-Packard 8450A spectrophotometer. Mass spectra were obtained at the Mass Spectrometry Facility at Louisiana State University. Benzaldehyde, $\mathrm{BF}_{3} \cdot \mathrm{OEt}_{2}$, dichloro-dicyanobenzoquinone (DDQ) were used as purchased. All solvents were dried and purified according to literature procedures.

\section{5,10,15,20-Tetra(4-nonanylphenyl)-2:3,7:8,12:13,17:18-tetrabutanoporphyrin (1b)}

was prepared from the condensation of 3:4-butanopyrrole $(0.25 \mathrm{~g}, 2.14 \mathrm{mmol})$ with 4nonanyl-benzaldehyde, in freshly distilled and dry dichloromethane $(214 \mathrm{~mL})$ and in the presence of $\mathrm{BF}_{3} \cdot \mathrm{OEt}_{2}(0.04 \mathrm{~mL}, 0.214 \mathrm{mmol})$, under argon. The reaction mixture was 
stirred for $1 \mathrm{~h}$ at room temperature, after which DDQ $(0.7 \mathrm{~g}, 3.21 \mathrm{mmol})$ was added and the final mixture was refluxed under argon for $1 \mathrm{~h}$ to give a dark green solution. The solvent was reduced to dryness under vacuum and the resulting residue purified by alumina column chromatography using $2 \%$ methanol in dichloromethane for elution. Recrystallization from hot methanol gave purple crystals of the title porphyrin $(0.5 \mathrm{~g}, 70 \%$ yield $)$, m.p. $>300$ ${ }^{\circ} \mathrm{C} .{ }^{1} \mathrm{H}-\mathrm{NMR}\left(\mathrm{CDCl}_{3}\right.$, drop of d-TFA), $\delta(\mathrm{ppm}), 8.10(\mathrm{~d}, 8 \mathrm{H}, \mathrm{J}=7.7 \mathrm{~Hz}) 7.91(\mathrm{~d}, 8 \mathrm{H}, \mathrm{J}=7.8$ Hz) 2.97-2.92, (t, 8H, J= 7.6 Hz) 2.33 (br s, 8H), 1.95-1.29 (m, 80H), 0.94-0.92 (t, 12H, J= 7.2 Hz). ${ }^{13} \mathrm{C}-\mathrm{NMR}\left(\mathrm{CDCl}_{3}\right)$ 144.1, 140.7, 136.2, 129.1, 118.5, 37.4, 33.5, 33.1, 31.29, 31.24, 30.97, 30.64, 27.3, 25.1, 24.2, 15.7. UV-Vis $\left(\mathrm{CH}_{2} \mathrm{Cl}_{2}\right) \lambda_{\max } 446 \mathrm{~nm}(\varepsilon 66,100), 542$ $\mathrm{nm}(5100), 615 \mathrm{~nm}$ (3700), $679 \mathrm{~nm}(55700)$, MS (MALDI) $\mathrm{m} / z .1335 .30\left(\mathrm{M}^{+}\right)$. Anal. Calcd for $\mathrm{C}_{96} \mathrm{H}_{126} \mathrm{~N}_{4}$ : C 84.03, H 9.56, $\mathrm{N}$ 4.09. Found: C 84.23, H 9.35, N 4.24. The 4nonanylbenzaldehyde was obtained from the reaction of 1-octylbromide $(50 \mathrm{mM}, 10.8 \mathrm{~g})$ in diethyl ether $(50 \mathrm{~mL})$ and under argon with magnesium turnings $(10 \mathrm{~g})$ at room temperature. After stirring for $30 \mathrm{~min}$ the reaction mixture was cooled to $0^{\circ} \mathrm{C}$ and bromobenzaldehyde $(40 \mathrm{mM}, 6.75 \mathrm{~g}$ ) was slowly added. The final mixture was allowed to stir for $1 \mathrm{~h}$ and then quenched and washed with water $(2 \times 50 \mathrm{~mL})$ and dried over $\mathrm{Na}_{2} \mathrm{SO}_{4}$. The organic solvents were evaporated under vacuum and the resulting yellow oil was taken up in hexane and purified by silica gel chromatography, using 3:1 hexane and ethyl acetate solution for elution. 1-(4-Bromophenyl)-1-hydroxynonane was obtained in $14.6 \mathrm{~g}\left(97 \%\right.$ yield); ${ }^{1} \mathrm{H}$ NMR $\left(\mathrm{CDCl}_{3}\right), \delta(\mathrm{ppm}), 7.45(\mathrm{~d}, 2 \mathrm{H}, \mathrm{J}=8.4 \mathrm{~Hz}), 7.20(\mathrm{~d}, 2 \mathrm{H}, \mathrm{J}=7.8 \mathrm{~Hz}), 4.61(\mathrm{~s}$, broad, 1H), 1.98 (s, 1H) 1.9-1.2 (m, 14H), $0.85\left(\mathrm{t}, 3 \mathrm{H}, \mathrm{J}=6.8 \mathrm{~Hz}\right.$ ). MS (FAB) $\mathrm{m} / z 299.17\left(\mathrm{M}^{+}\right)$. To a solution of 1-(4-bromophenyl)-1-hydroxynonane $(50 \mathrm{mM}, 14.9 \mathrm{~g})$ in $150 \mathrm{~mL}$ of acetonitrile, (300 mM, $27 \mathrm{~mL}$ ) of trimethylsilylchloride (TMSC) and (300 mM, $45 \mathrm{~g})$ of sodium iodide were added and the final mixture was stirred under argon for $12 \mathrm{~h}$ at room temperature. The reaction mixture was washed with an aqueous solution of $\mathrm{Na}_{2} \mathrm{~S}_{2} \mathrm{O}_{3}$, dried over $\mathrm{Na}_{2} \mathrm{SO}_{4}$ and the organic solvent evaporated under reduced pressure affording an orange oil. The orange oil was diluted with $150 \mathrm{~mL}$ of DMSO and $(750 \mathrm{mM}, 2.85 \mathrm{~g})$ of $\mathrm{NaBH}_{4}$ was slowly added. The resulting solution was stirred under argon for $12 \mathrm{~h}$ and then extracted into hexane and purified by silica gel chromatography using hexane for elution. The first band collected was 4-bromophenylnonane $(10.7 \mathrm{~g}, 76.3 \%) .{ }^{1} \mathrm{H}-\mathrm{NMR}\left(\mathrm{CDCl}_{3}\right), \delta(\mathrm{ppm}), 7.42(\mathrm{~d}$, $2 \mathrm{H}, \mathrm{J}=8.4 \mathrm{~Hz}), 7.08(\mathrm{~d}, 2 \mathrm{H}, \mathrm{J}=7.8 \mathrm{~Hz}), 2.60(\mathrm{t}, 2 \mathrm{H}, \mathrm{J}=7.6 \mathrm{~Hz}) 1.58-1.29(\mathrm{~m}, 14 \mathrm{H}), 0.91(\mathrm{t}$, $3 \mathrm{H}, \mathrm{J}=7.2 \mathrm{~Hz}$ ). MS (FAB) $\mathrm{m} / \mathrm{z} 282.16\left(\mathrm{M}^{+}\right)$. 4-Bromophenylnonane $(15 \mathrm{mM}, 4.25 \mathrm{~g})$ was dissolved in freshly distilled THF $(50 \mathrm{~mL})$ and the reaction mixture cooled to $-78^{\circ} \mathrm{C}$. $\mathrm{n}$ $\mathrm{BuLi}(46 \mathrm{mM}, 26.5 \mathrm{~mL})$ was then added dropwise and the mixture was stirred at $-78^{\circ} \mathrm{C}$ for $1 \mathrm{~h}$. Dry DMF ( $46 \mathrm{mM}, 3.0 \mathrm{~mL}$ ) was then added dropwise and the final mixture stirred under argon for $1 \mathrm{~h}$. The reaction mixture was allowed to warm up to room temperature and then quenched with $100 \mathrm{~mL}$ of $1 \mathrm{M} \mathrm{HCl}$. The mixture was extracted into hexanes $(3 \times 100$ $\mathrm{mL})$, washed with water $(2 \times 100 \mathrm{~mL})$, dried over $\mathrm{Na}_{2} \mathrm{SO}_{4}$ and the solvent removed under reduced pressure to give a yellow oil. 4-Nonanylbenzaldehyde was purified by silica gel chromatography using a 3:1 solution of hexane/ethyl acetate for elution to give an oil ( $2.3 \mathrm{~g}$, $65 \%$ yield). ${ }^{1} \mathrm{H}-\mathrm{NMR}\left(\mathrm{CDCl}_{3}\right), \delta(\mathrm{ppm}), 10.0(\mathrm{~s}, 1 \mathrm{H}) 7.82(\mathrm{~d}, 2 \mathrm{H}, \mathrm{J}=8.4 \mathrm{~Hz}), 7.36(\mathrm{~d}, 2 \mathrm{H}$, $\mathrm{J}=7.8 \mathrm{~Hz}), 2.74(\mathrm{~m}, 2 \mathrm{H}) 1.69-1.29(\mathrm{~m}, 14 \mathrm{H}), 0.93(\mathrm{t}, 3 \mathrm{H}, \mathrm{J}=7.2 \mathrm{~Hz})$. MS (FAB) $\mathrm{m} / z 233.26$ $\left(\mathrm{M}^{+}\right)$.

\section{Benzoylbiliverdins 2a and 3a}

were prepared and characterized as we have previously described. ${ }^{24}$

\section{Benzoylbiliverdins $2 b$ and $3 b$}

Porphyrin $1 \mathbf{b}$ (100 mg, $0.074 \mathrm{mmol})$ was dissolved in $2 \mathrm{~mL}$ of TFA and $\mathrm{NaNO}_{2}(30 \mathrm{mg}$, $0.45 \mathrm{mM}$ ) was added to the solution while stirring under air at room temperature for $3 \mathrm{~min}$. The reaction was quenched by pouring into $50 \mathrm{~mL}$ of water, following by extraction with dichloromethane $(6 \times 25 \mathrm{~mL})$. The organic layers were washed with saturated aqueous 
$\mathrm{NaHCO}_{3}(2 \times 100 \mathrm{~mL})$, then with water $(100 \mathrm{~mL})$, and dried over anhydrous $\mathrm{Na}_{2} \mathrm{SO}_{4}$. The solvent was removed under vacuum and the resulting residue was taken up in chloroform and purified by alumina column chromatography using a gradient elution of chloroform to $1 \%$ methanol in chloroform. The title biliverdin $\mathbf{2 b}$ was the first green band eluted using pure chloroform (71 mg, 70\%). The benzoylbiliverdin $\mathbf{3 b}$ (violet color) was eluted next using $1 \%$ methanol in chloroform solution $(15 \mathrm{mg}, 15 \%)$ yield. For the title biliverdin $\mathbf{2 b}$ : m.p. $=245-247^{\circ} \mathrm{C}$. UV-Vis $\left(\mathrm{CH}_{2} \mathrm{Cl}_{2}\right) \lambda_{\max } 332 \mathrm{~nm}(\varepsilon 30600), 447$ (31600), 683 (7800). MS (MALDI-TOF) $\mathrm{m} / z, 1368.3\left(\mathrm{M}^{+}\right) .{ }^{1} \mathrm{H}$ NMR $\left(\mathrm{CDCl}_{3}\right), \delta(\mathrm{ppm}), 12.80$ (br s, $\left.1 \mathrm{H}\right), 10.80$ (br s, $1 \mathrm{H}), 8.22-6.75(\mathrm{~m}, 16 \mathrm{H}), 2,76-1.33(\mathrm{~m}, 96 \mathrm{H}), 0.94(\mathrm{~m}, 12 \mathrm{H})$ : Anal. Calcd for $\mathrm{C}_{96} \mathrm{H}_{126} \mathrm{~N}_{4} \mathrm{O}_{2}$ : C 80.05, H 9.38, N 3.89. Found: C 80.07 H 9.07, N 3.83. For biliverdin 3b: m.p. $=185-190$ ${ }^{\circ} \mathrm{C}$; UV-Vis $\left(\mathrm{CH}_{2} \mathrm{Cl}_{2}\right) \lambda_{\max } 345 \mathrm{~nm}(\varepsilon 47100), 576 \mathrm{~nm}$ (22700). MS (MALDI-TOF) $\mathrm{m} / \mathrm{z}$ $1386.4\left(\mathrm{M}^{+}\right) .{ }^{1} \mathrm{H}$ NMR $\left(\mathrm{CDCl}_{3}\right), \delta(\mathrm{ppm}), 11.52,11.45(2 \mathrm{br} \mathrm{s}, 2 \mathrm{H}), 8.86(\mathrm{~s}, 1 \mathrm{H}), 7.56(\mathrm{~d}, J=$ $8.0 \mathrm{~Hz}, 2 \mathrm{H}), 7.40(\mathrm{~d}, J=8.0 \mathrm{~Hz}, 2 \mathrm{H}), 7.3-7.1(\mathrm{~m}, 12 \mathrm{H}), 6.10(\mathrm{~s}, 1 \mathrm{H}), 2.7-1.24(\mathrm{~m}, 96 \mathrm{H}), 0.94$ (br s, $12 \mathrm{H}) .{ }^{13} \mathrm{C}-\mathrm{NMR}\left(\mathrm{CDCl}_{3}\right), \delta(\mathrm{ppm}), 172.2,163.5,146.6,145.3,144.3,143.5,143.2$, 139.6, 138.8, 137.7, 136.6, 135.6, 135.1, 134.2, 133.5, 131.1, 129.8, 128.9, 128.5, 128.3, $127.2,125.3,120.6,119.4,74.1,36.1,35.8,35.7,32.1,31.8,31.6,29.8,29.7,29.6,29.5$, 29.1, 24.9, 24.1, 23.4, 23.0, 22.9. Anal. Calcd for $\mathrm{C}_{96} \mathrm{H}_{128} \mathrm{~N}_{4} \mathrm{O}_{3}$ : C 83.19, H 9.31, N 4.04. Found: C 82.98, H 9.24, N 4.12.

\section{Crystal Molecular structures}

Bilatrienone 2b, $\mathrm{C}_{96} \mathrm{H}_{126} \mathrm{~N}_{4} \mathrm{O}_{2} \cdot \mathrm{H}_{2} \mathrm{O} \cdot \mathrm{MeOH}, \mathrm{M}_{r}=1418.1$, triclinic, space group P-1, a = 14.222(5), $\mathrm{b}=16.640(6), \mathrm{c}=19.510(10) \AA, \alpha=92.097(14), \beta=103.467(15), \gamma=$ $107.381(19)^{\circ}, V=4257(3) \AA^{3}, Z=2$, Mo-K $\alpha$ radiation $\left(\lambda=0.71073 \AA ;=\mu=0.066 \mathrm{~mm}^{-1}\right)$, $\mathrm{T}=110 \mathrm{~K}, 22253$ data by Nonius Kappa CCD, $\mathrm{R}=0.122\left(\mathrm{~F}^{2}>2 \sigma\right)$, for 11688 unique data having $\theta_{\max }=23.0^{\circ}$ and 906 refined parameters. Displacement parameters are large for three of the nonanyl groups, and anisotropic refinement of one of them was not possible. Solvent H atoms were not located. CCDC 745873, available from the Cambridge Crystallographic Data Centre.

Biladienone 3a, $\mathrm{C}_{60} \mathrm{H}_{56} \mathrm{~N}_{4} \mathrm{O}_{3} \cdot \mathrm{CH}_{2} \mathrm{Cl}_{2}, \mathrm{M}_{\mathrm{r}}=966.01$, triclinic, space group P-1, a = 12.483(10), $\mathrm{b}=13.993(12), \mathrm{c}=16.320(17) \AA, \alpha=75.65(3), \beta=75.83(3), \gamma=67.91(6)^{\circ}, \mathrm{V}=$ 2522(4) $\AA_{3}, Z=2$, Mo-K $\alpha$ radiation $\left(\lambda=0.71073 \AA\right.$; $\left.\mu=0.180 \mathrm{~mm}^{-1}\right), \mathrm{T}=110 \mathrm{~K}, 26049$ data by Nonius Kappa CCD, $R=0.151\left(\mathrm{~F}^{2}>2 \sigma\right)$ for 6470 unique data having $\theta_{\max }=23.1^{\circ}$ and 306 refined parameters. As a result of the small number (1771) of unique intensities having I>2 (I), only $\mathrm{O}$ and solvent $\mathrm{Cl}$ atoms were refined anisotropically. CCDC 745874, available from the Cambridge Crystallographic Data Centre.

\section{Conclusions}

It is shown that bilitrienones $\mathbf{2}$ are obtained from oxidation of metal-free dodecasubstituted porphyrins 1 in the presence of sodium nitrite, trifluoroacetic acid and air oxygen. Bilitrienone $\mathbf{2 b}$ is obtained from the 5,10,15,20-tetra( $p$-nonanylphenyl)porphyrin $\mathbf{1 b}$, this being the first example of the unmodified metal-free open-chain tetrapyrrole to be reported; the structure of $\mathbf{2 b}$ is characterized by X-ray crystallography. In the absence of the paranonanyl groups the initially-formed bilitrienone $2 \mathrm{a}$ undergoes a rapid and spontaneous hydration reaction to give biladienone $\mathbf{3 a}$ as the major isolated product. The molecular structure of $\mathbf{3 a}$ is also presented.

\section{Acknowledgments}

Support from the National Institutes of Health (CA 132861 to K.M.S.) and the National Science Foundation (CHE 0911629 to M.G.H.V.) is gratefully acknowledged. 


\section{References}

1. Ortiz de Montellano, PR.; Auclair, K. The Porphyrin Handbook. Kadish, KM.; Smith, KM.; Guilard, R., editors. Vol. Vol. 12. Boston: Academic Press; 2003. p. 183-210.

2. Kräutler, BA. The Porphyrin Handbook. Kadish, KM.; Smith, KM.; Guilard, R., editors. Vol. Vol. 13. Boston: Academic Press; 2003. p. 183-209.

3. (a) Frankenberg, N.; Lagarias, JC. The Porphyrin Handbook. Kadish, KM.; Smith, KM.; Guilard, R., editors. Vol. Vol. 13. Boston: Academic Press; 2003. p. 211-235.(b) Gossauer, A. The Porphyrin Handbook. Kadish, KM.; Smith, KM.; Guilard, R., editors. Vol. Vol. 13. Boston: Academic Press; 2003. p. 237-274.

4. Braslavsky SE, Holzwarth AR, Schaffner K. Angew. Chem. Int. Ed. Engl 1983;22:656-674.

5. Koerner R, Olmstead MM, Ozarowski A, Balch AL. Inorg. Chem 1999;38:3262-3263. [PubMed: 11671055]

6. Stocker R, Yamamoto Y, McDonagh AF, Glazer AN, Ames BN. Science 1987;235:1043-1046. [PubMed: 3029864]

7. Nakagami T, Taji S, Takahashi M, Yamanishi K. Microbiol. Immunol 1992;36:381-390. [PubMed: 1328826]

8. Bennett, A.; Siegelman, HW. The Porphyrin. Dolphin, D., editor. Vol. Vol. 6. New York: Academic Press; 1979. p. 493-520.

9. Mori H, Otake T, Morimoto M, Ueba N, Kunita N, Nakagami T, Yamasaki N, Taji S. Jpn. J. Cancer Res 1991;82:755-757. [PubMed: 1715337]

10. Schmid, R.; McDonagh, AF. Formation and metabolism of bile pigments in vivo. In: Dolphin, D., editor. The Porphyrins. Vol. Vol 6. New York: Academic Press; 1979. p. 257-292.

11. Frydman RB, Frydman B. Acc. Chem. Res 1987;20:250-256.

12. Smith KM, Kishore D. Tetrahedron 1983;39:1841-1847.

13. Cavaleiro JAS, Smith KM. J. Chem. Soc. Perkin Trans. 1 1973:2149-2155.

14. (a) Boiadjiev EE, Lightner DA. Tetrahedron: Assymmetry 2001;12:2551-2564. (b) Kar AK, Lightner DA. Tetrahedron 1998;54:12671-12690.

15. Smith KM. J. Chem. Soc., Perkin Trans 1 1972:1471-1475.

16. (a) Bonnett R, McDonagh AF. J. Chem. Soc., Chem. Commun 1970:237-238. (b) Bonnett R, McDonagh AF. J. Chem. Soc., Perkin Trans. 1 1973:881-888.

17. Crusats J, Suzuki A, Mizutani T, Ogoshi H. J. Org. Chem 1998;63:602-607. [PubMed: 11672050]

18. (a) Evans B, Smith KM, Cavaleiro JAS. Tetrahedron Lett 1976:4863-4866. (b) Evans B, Smith KM, Cavaleiro JAS. J. Chem. Soc., Perkin Trans. I 1978:768-773.

19. Fuhrhop J-H, Mauzerall D. Photochem. Photobiol 1971;13:453-458.

20. Wasser PKW, Fuhrhop J-H. Ann. N.Y. Acad. Sci 1973;206:533-547. [PubMed: 4518405]

21. Catalano MM, Crossley MJ, Harding MM, King LG. J. Chem. Soc., Chem. Commun 1984:15351536.

22. Ongayi O, Fronczek F, Vicente MGH. Chem. Commun 2003:2298-2299.

23. Bonnett R, Dimsdale MJ. J. Chem. Soc., Perkin Trans. 1 1972:2540-2548.

24. Ongayi O, Vicente MGH, Ou Z, Kadish KM, Kumar MR, Fronczek FR, Smith KM. Inorg. Chem 2006;45:1463-1470. [PubMed: 16471957]

25. Shine HJ, Padilla AG, Wu S-M. J. Org. Chem 1979;44:4069-4075.

26. (a) Smith KM, Brown SB, Troxler RF, Lai J-J. Tetrahedron Lett 1980;21:2763-2766. (b) Smith KM, Brown SB, Troxler RF, Lai J-J. Photochem. Photobiol 1982;36:147-152. [PubMed: 7122709]

27. Matsuura T, Inoue K, Ranade AC, Saito I. Photochem. Photobiol 1980;31:23-26.

28. (a) Cavaleiro JAS, Hewlins MJE, Jackson AH, Neves MGPMS. J. Chem. Soc., Chem. Commun 1986:142-144. (b) Cavaleiro JAS, Neves MGPMS, Hewlins MJE, Jackson AH. J. Chem. Soc., Perkin Trans. I 1990:1937-11943.

29. Yamauchi T, Mizutani T, Wada K, Horii S, Furukawa H, Shigeyuki Masaoka, Chang H, Kitagawa S. Chem. Commun 2005:2298-2299. 
30. Scheer H. Angew. Chem., Int. Ed. Eng 1981;20:241-261. and references therein.

31. Niemevz F, Buldain YG. J. Porphyrins Pthalocyanines 2004;8:989-995.

32. Iturraspe JB, Bari S, Frydman B. J. Am. Chem. Soc 1989;111:1525-1527.

33. Blauer G, Wagniere G. J. Am. Chem. Soc 1975;97:1949-1954. [PubMed: 237049]

34. Pasternak R, Wagniere G. J. Am. Chem. Soc 1979;101:1662-1667.

35. Burke MJ, Pratt DC, Moscowitz A. Biochemistry 1972;11:4025-4031. [PubMed: 5086537]

36. Falk H, Hoellbacher G. Monatsh. Chem 1978;109:1429-1449.

37. Wagniere G, Blauer G. J. Am. Chem. Soc 1976;98:7806-7810. [PubMed: 993498]

38. (a) Falk H, Muller N, Schlederer T. Monatsh.Chem 1980;111:159-175. (b) Falk H, Grubmayr K, Haslinger E, Schlederer T, Thirring K. Ibid 1978;109:1451-1473. (c) Falk H, Grubmayr K. Angew. Chem 1977;89:487-488. 


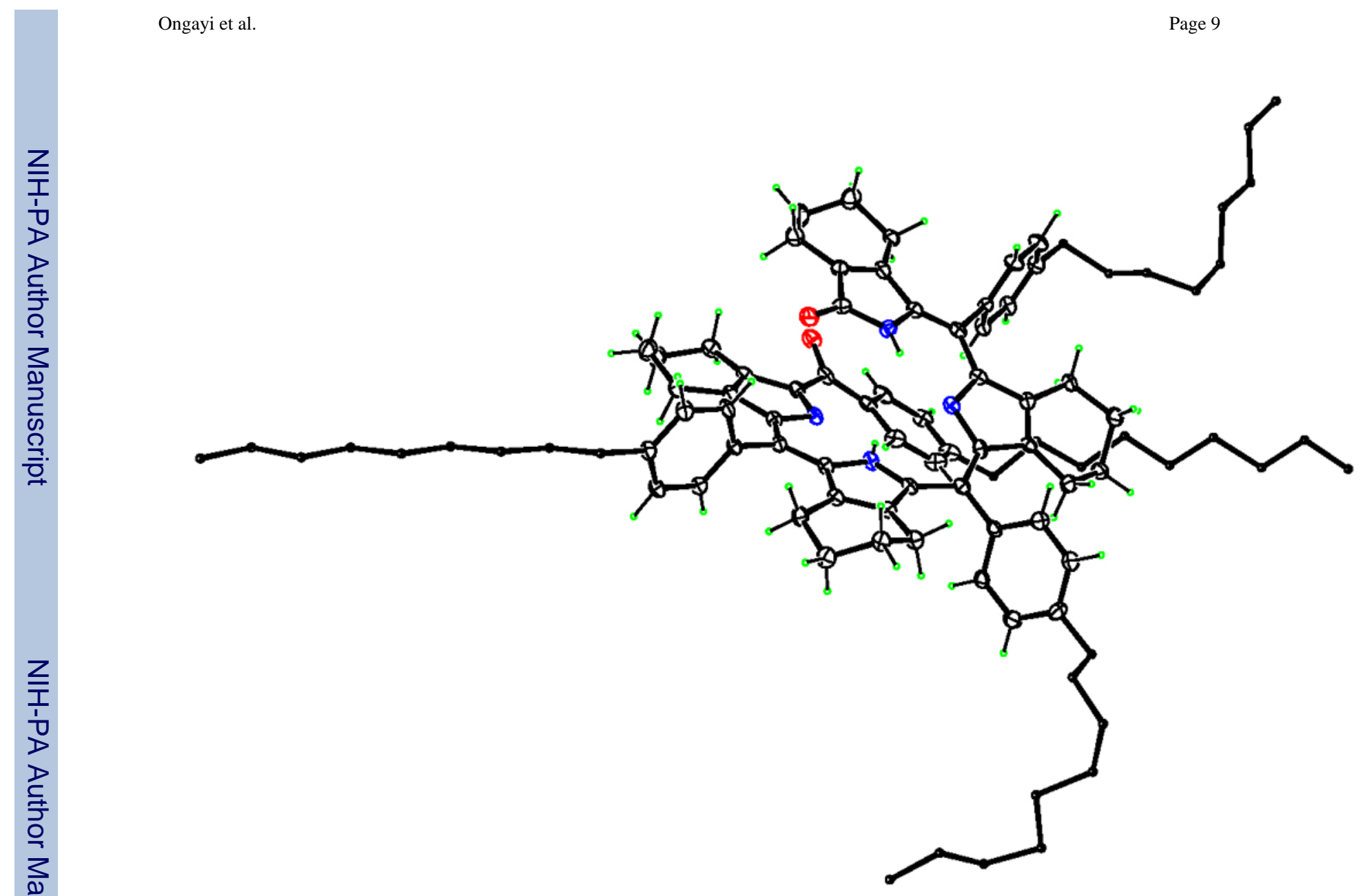

Figure 1.

ORTEP diagram showing the molecular structure of $\mathbf{2 b}$. 


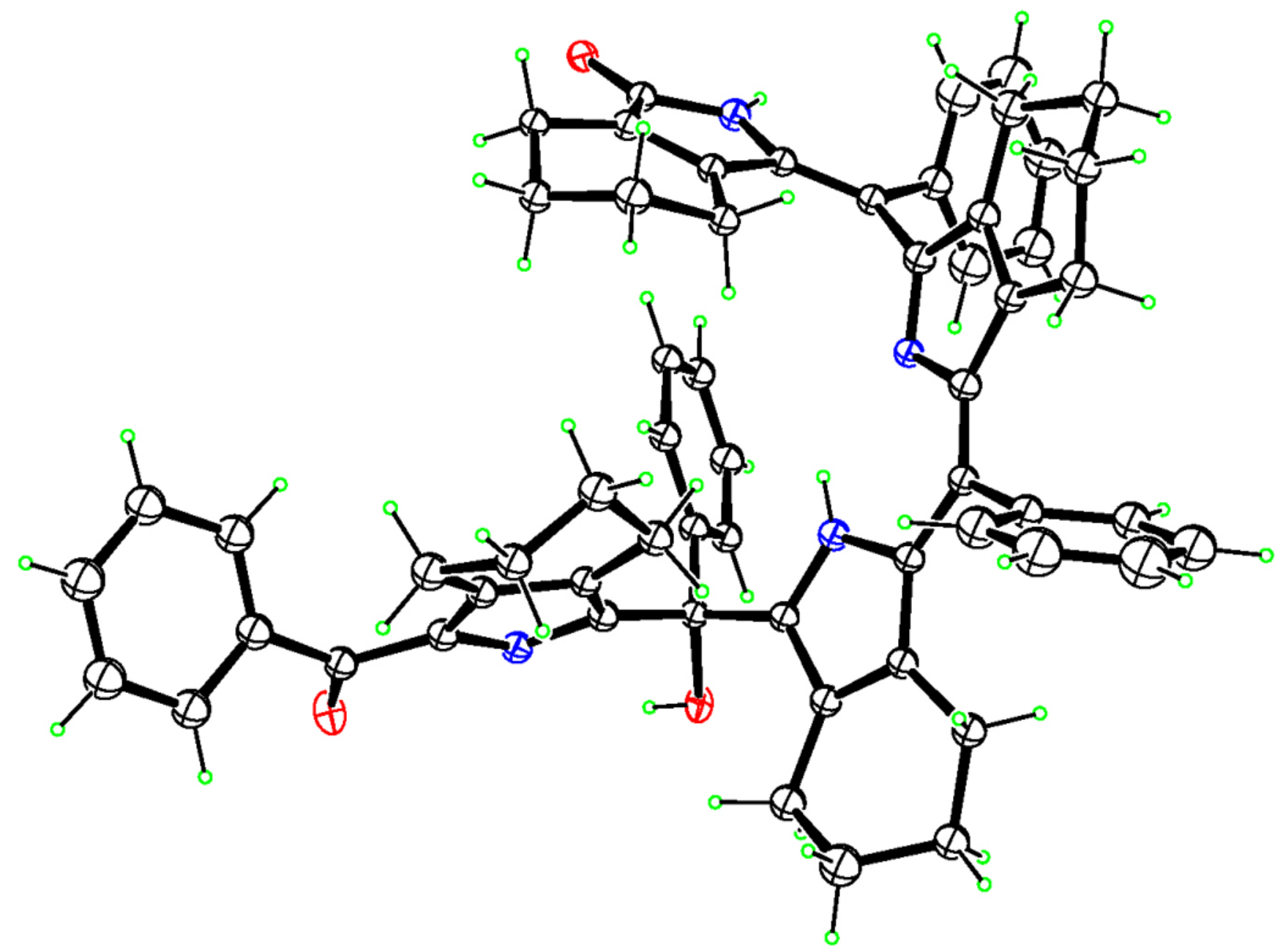

Figure 2.

ORTEP diagram showing the molecular structure of $\mathbf{3 a}$. 


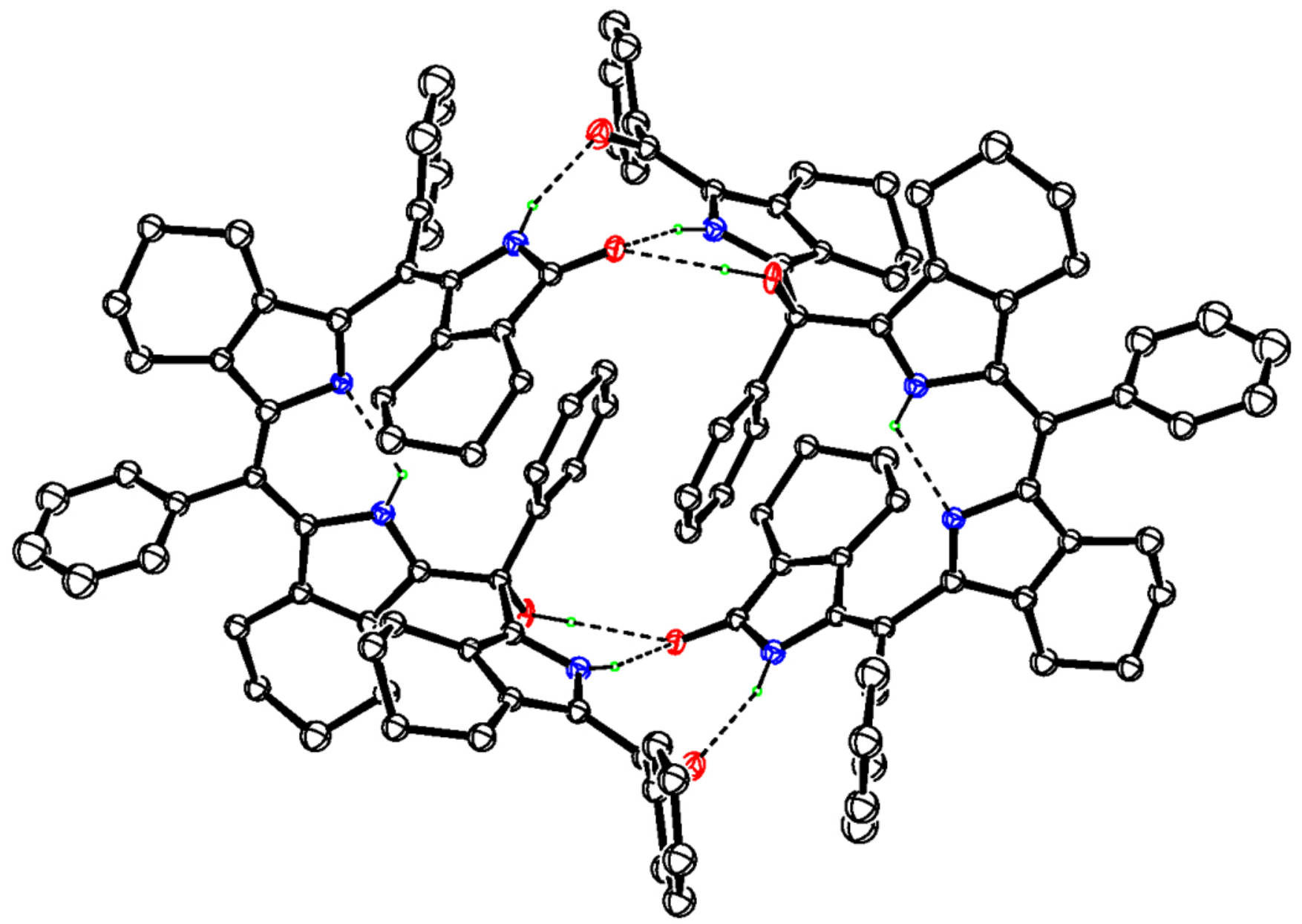

Figure 3.

ORTEP diagram of 3a pair showing hydrogen bonding. 